\title{
TRAJETÓRIA HISTÓRICA DAS POLÍTICAS PÚBLICAS PARA A EDUCAÇÃO DE JOVENS E ADULTOS NO BRASIL
}

\author{
HISTORICAL PATH OF PUBLIC POLICIES FOR THE \\ YOUTH AND ADULT EDUCATION IN BRAZIL
}

\author{
Bruna de Souza Pereira Santos. ${ }^{1}$ \\ Adrian Alvarez Estrada ${ }^{2}$
}

http://dx.doi.org/10.52641/cadcaj.v6i4.442

RESUMO: Considerando o histórico da Educação de Jovens e Adultos no Brasil, bem como, as
políticas públicas voltadas para esta modalidade da educação, o presente trabalho tem por objetivo
analisar a trajetória histórica da Educação de Jovens e Adultos no Brasil, desde o século XVI com
a colonização portuguesa até os dias atuais, no sentido de identificar os principais marcos legais
que organizaram a (EJA) em nosso país até se tornar uma modalidade de educação. Para atingir o
objetivo proposto, foi realizado estudo bibliográfico e documental tomando como base para a
investigação os documentos oficiais e autores que tratam sobre a trajetória histórica da (EJA) no
Brasil, assim foi possível identificar e analisar os avanços obtidos nesta modalidade de educação,
juntamente com as transformações políticas, econômicas, sociais e culturais da sociedade brasileira.

Palavras-chaves: Educação de Jovens e Adultos. Políticas Públicas. Trajetória Histórica.

\begin{abstract}
Considering the history of Youth and Adult Education in Brazil, as well as public policies aimed at this modality of education, the present work aims to analyze the historical trajectory of Youth and Adult Education in Brazil, since the 16th century with the Portuguese colonization to the present day, in order to identify the main legal frameworks that organized (EJA) in our country until it became a modality of education. To achieve the proposed objective, a bibliographic and documentary study was carried out, based on the investigation, the official documents and authors dealing with the historical trajectory of (EJA) in Brazil, thus it was possible to identify and analyze the advances obtained in this modality of education, along with the political, economic, social and cultural transformations of Brazilian society.
\end{abstract}

Key-words: Youth and Adult Education. Public Policy. Historical Trajectory.

\section{INTRODUÇÃO}

\footnotetext{
${ }^{1}$ Mestre em Educação pela Universidade Estadual do Oeste do Paraná (UNIOESTE), Campus de Cascavel. E-mail: brunasps.10@gmail.com

2 Professor e coordenador do Programa de Pós-Graduação em Educação da Universidade Estadual do Oeste do Paraná (UNIOESTE), Campus de Cascavel. Doutor em Educação pela Universidade de São Paulo (USP). E-mail: adrianalvarez.estrada@gmail.com
} 
Os fatores que motivaram a realização desta pesquisa estão vinculados a minha atuação como professora alfabetizadora da Educação de Jovens e Adultos (EJA) - Fase I e posteriormente como Coordenadora Pedagógica Municipal desta modalidade de Ensino, na Secretaria Municipal de Educação (SEMED) de Cascavel.

Durante minha atuação como professora nesta modalidade de ensino é que tive a real constatação que ainda existe um número significativo de pessoas jovens e adultas que não conseguiram terminar seu processo de escolarização em série compatível com a idade. Como professora tinha a oportunidade de contribuir para a melhoria de vida daqueles alunos que, por diferentes motivos, tiveram negado o direito de acesso à educação ao longo de suas vidas.

O objetivo deste artigo é analisar a trajetória histórica da (EJA) no Brasil, para tanto, será apresentado um breve histórico, desde o século XVI com a colonização portuguesa até os dias atuais, no sentido de identificar os principais marcos legais que organizaram a (EJA) em nosso país até se tornar um modalidade de educação.

Para a efetivação do artigo foi realizado estudo bibliográfico e documental tomando como base para a investigação os documentos oficiais. A pesquisa de ordem bibliográfica é aquela que se realiza a partir do registro disponível, decorrente de pesquisas anteriores, em documentos impressos, como livros, artigos, teses etc. (SEVERINO, 2007, p. 122).

A intenção foi realizar uma aproximação teórica com o objeto de estudo, por meio de uma investigação analítica, tendo como suporte obras existentes, artigos, dissertações e sites oficiais que disponibilizam dados que fundamentam o estudo.

Por fim, apresentaremos as considerações finais sobre o objeto investigado, as quais não esgotam o assunto, mas contribuem para a sistematização da análise realizada.

\section{DESENVOLVIMENTO}

Considerando que a organização educacional, embora se estabeleça de acordo com a sociedade a que serve, reflete as condições sociais, econômicas e políticas dessa sociedade, é importante analisar essa organização a fim de apontar possíveis caminhos para a manutenção de uma educação de qualidade e, ao mesmo tempo, emancipadora. As características dos diferentes períodos históricos da educação de um país acompanham seu movimento histórico, suas transformações econômicas e sociais e suas lutas sobre o poder político. Neste sentido, atua como expressão das relações sociais, pois:

Toda educação provém de uma situação social determinada e as metas educacionais, a política da educação e a orientação do ensino mostram de forma 
clara o seu caráter histórico. Por outro lado, a forma como o movimento da sociedade se reflete na educação pode ser observada mais claramente sempre que se inicia um período de transformações e o sistema educacional existente (ou em formação) já não atende às novas necessidades criadas, necessitando ou de ampliação urgente ou de movimentos paralelos que preencham as lacunas deixadas pela organização do ensino vigente (PAIVA, 2015, p. 29).

A justificativa para as mudanças no sistema educacional se dá pelas condições políticas, sociais e econômicas de cada momento histórico.

Desde a colonização portuguesa, constata-se a existência de políticas para a educação de jovens e adultos focadas e restritas, sobretudo aos processos de alfabetização, de modo que é muito recente a conquista, o reconhecimento e a definição desta modalidade como política pública de acesso e continuidade à escolarização básica.

A preocupação com a escolarização de adultos não alfabetizados iniciou no século XVI com a colonização portuguesa. Neste período a educação proporcionada aos índios, tinha caráter religioso, com o objetivo de disseminar os ideais da igreja católica e expandir a cultura europeia (HADDAD, 1991, p. 1). Através do ensino das crianças os Jesuítas buscavam também atingir seus pais, bem como a tentativa de apresentar a catequese direta dos indígenas adultos. Nessas situações a alfabetização e transmissão do idioma português servia como instrumento de cristianização e aculturação dos nativos (PAIVA, 2015, p. 193).

Assim, é possível afirmar que a EJA não é algo recente na educação brasileira, conforme afirmam Haddad e Di Pierro:

A ação educativa junto a adolescentes e adultos no Brasil não é nova. Sabe-se que
já no período colonial os religiosos exerciam sua ação educativa missionária em
grande parte com adultos. Além de difundir o evangelho, tais educadores
transmitiam normas de comportamento e ensinavam os ofícios necessários ao
funcionamento da economia colonial, inicialmente aos indígenas e,
posteriormente, aos escravos negros. Mais tarde, se encarregaram das escolas de
humanidades para os colonizadores e seus filhos. (2000, p.108-109).

Após a fase inicial de colonização, a educação dos indígenas adultos foi perdendo a sua importância, sendo que as atividades econômicas coloniais não exigiam o estabelecimento de escolas para a população adulta, composta de portugueses e seus descendentes e ainda menos para a população escrava. Conforme afirma Paiva (2015):

O domínio das técnicas da leitura e da escrita não se mostrava muito necessário ao cumprimento das tarefas exigidas aos membros daquela sociedade colonial. $\mathrm{Na}$ verdade, só encontraremos tais escolas quando, já no Império, a sociedade brasileira começa a se transformar em face às novas condições de sua economia (PAIVA, 2015, p. 193). 
Porém, com o progresso iniciado por volta de 1870, determina-se o surgimento de escola para adultos. Tal progresso acompanha o crescimento do sistema elementar de ensino em geral, o que ocorre durante os últimos anos do Império e início da Primeira República (PAIVA, 2015, p. 193).

Nesse período:

[...] as escolas noturnas se multiplicaram na maioria das províncias do Império, através da iniciativa oficial, contando no país com 117 dessas escolas em 1876. Entre 1870 e 1880 praticamente todas as províncias criam esse tipo de ensino [...] (PAIVA, 1987, p. 167).

Pode-se dizer então, que somente a partir do Império, com a criação, em quase todas as províncias do país, das chamadas "escolas noturnas", é que se encontram iniciativas no campo da educação de jovens e adultos.

Antes dessa iniciativa do Império, a Carta Magna de 1824 garante, em seu Artigo 179, Parágrafo XXXII, que a "instrução primária é gratuita para todos os cidadãos". Porém, essa instrução era vedada aos escravos, as mulheres, e não era obrigatória, fatos que dão o tom do que era concebido como cidadania naquele tempo. O preconizado para a educação de adultos nesta Carta Magna deve-se ao processo de urbanização, ao lado do processo de industrialização, que ocasionou grandes transformações na sociedade, necessidade de mão-de-obra eficaz, necessidade de aumentar e fortalecer as bases eleitorais (SMED, 2007, p. 13).

Diante do exposto, compreendemos que a EJA no Brasil sempre se relacionou com os interesses políticos e econômicos das elites.

No período após a Primeira Guerra Mundial, por volta de 1919, a mobilização em relação à educação de forma geral, fez com que a educação de adultos se beneficiasse levemente, não havendo, portanto, uma iniciativa específica para a educação de adultos.

A partir de 1930, quando a sociedade brasileira atravessava grandes transformações em virtude do processo de industrialização e concentração populacional nos centros urbanos, é que a educação de adultos passa a ter maior importância. Somente a partir da revolução de 30 encontraremos no país movimentos de educação de adultos de alguma significação (PAIVA, 2015, p. 193).

Até então, era necessário erradicar o analfabetismo que assolava a maioria da população brasileira, porém, a educação deveria formar pessoas não críticas, para que, de posse dos conhecimentos, o povo não se rebelasse contra os governantes e que a domesticação intelectual pudesse continuar na organização da sociedade.

Paiva (1987) afirma que nos anos subsequentes a década de 1920, ocorreram grandes agitações sociais no sentido de refletir sobre as transformações ocorridas na sociedade brasileira 
nos anos que sucederam a Primeira Grande Guerra e em consequência a luta pela recomposição do poder político.

De acordo com a história educacional do país, foi entre os anos de 1930 a 1945 que se apresenta fases bastante diferenciadas refletindo diretamente na esfera educativa tendo como consequências as transformações do regime político.

Assim, a Constituição de 1934, em seu Artigo 150, alínea a, garante o "ensino primário integral, gratuito e de frequência obrigatória extensiva aos adultos". Além dessa garantia constitucional, alguns cursos de continuidade e aperfeiçoamento foram criados para aos jovens e adultos. Conforme afirma Sales:

[...] eram cursos práticos de artes e ofícios destinados a quem quer que fosse e cursos de aperfeiçoamento para os que já tinham alguma profissão definida. Instalaram-se ainda os cursos de oportunidades, cuja organização variava de acordo com os interesses dos alunos e das oportunidades de emprego e atividades existentes no mercado de trabalho (SALES, 2008, p. 28).

No entanto, Sales (2008) afirma que tais cursos tiveram pouca duração devido à alegação do presidente Getúlio Vargas de que tais cursos serviam de propagadores dos ideais comunistas.

A partir da década de 1940, então, é que se observam os elevados índices de analfabetismo no Brasil. É nesse período que a Educação de Jovens e Adultos toma forma de Campanha Nacional de Massa. Mais precisamente, no ano de 1947, o governo lança a Primeira Campanha de Educação de Adultos com a seguinte proposta: alfabetização dos adultos em três meses; oferta de um curso primário em duas etapas de sete meses e a capacitação profissional e o desenvolvimento comunitário (CUNHA, 1999).

Esta Campanha, segundo Eugênio:

[...] era vista como uma autêntica campanha de salvação nacional. Tentava conciliar quantidade com a qualidade e a continuidade do ensino. Entretanto, predominou tão somente o aspecto quantitativo, pois a intenção qualitativa nunca chegou a se concretizar (EUGÊNIO, 2004, p. 31).

Dessa forma, no início da Segunda República, a educação de adultos passou a ser vista como veículo de difusão de ideias com caráter ideológico. De acordo com Paiva (2015):

[...] com a reabertura da vida política no final do Estado Novo e as primeiras tentativas de Vargas de ganhar a simpatia das esquerdas, se oferecerá a oportunidade para o surgimento de novos movimentos de educação das massas, já então com caráter iminentemente político. A educação dos adultos aparecia como um meio e um aspecto da organização política das massas (PAIVA, 2015, p. 195). 
Assim, a primeira iniciativa pública ocorreu na década de 1940 e as ações desenvolvidas pelo Estado para a EJA apresentavam-se, mesmo que enquanto produto da demanda social, e de maneira estratégica, considerando que:

[...] as políticas sociais conduzidas pelo Estado capitalista representam um resultado da relação e do complexo desenvolvimento das forças produtivas e das forças sociais. Elas são o resultado da luta de classes e ao mesmo tempo contribuem para a reprodução das classes sociais (FALEIROS, 2009, p.46).

Neste período o Ministério da Educação e Saúde lançou a Primeira Campanha Nacional de Educação de Adultos. A criação da Organização das Nações Unidas - ONU, no período pósguerra, desencadeou um processo de recomendações aos países com alto índice de analfabetismo para que organizassem campanhas de massa para alfabetização (PAIVA 2015). Paiva apresenta o objetivo da Campanha segundo o Ministério da Educação:

[...] as políticas sociais conduzidas pelo Estado capitalista representam um resultado da relação e do complexo desenvolvimento das forças produtivas e das forças sociais. Elas são o resultado da luta de classes e ao mesmo tempo contribuem para a reprodução das classes sociais (FALEIROS, 2009, p.46).

Neste período o Ministério da Educação e Saúde lançou a Primeira Campanha Nacional de Educação de Adultos. A criação da Organização das Nações Unidas - ONU, no período pósguerra, desencadeou um processo de recomendações aos países com alto índice de analfabetismo para que organizassem campanhas de massa para alfabetização (PAIVA 2015). Paiva apresenta o objetivo da Campanha segundo o Ministério da Educação:

[...] a educação dos adultos convertera-se num requisito indispensável para "uma melhor organização e reorganização social com sentido democrático e num recurso social da maior importância, para desenvolver entre as populações adultas marginalizadas o sentido de ajustamento social. A campanha significava o combate ao marginalismo, conforme os pronunciamentos de Lourenço Filho: "devemos educar os adultos, antes de tudo, para que esse marginalismo desapareça, e o país possa ser mais coeso e mais solidário; devemos educá-los para que cada homem ou mulher melhor possa ajustar-se à vida social e às preocupações de bem-estar e progresso social. E devemos educá-los porque essa é a obra de defesa nacional, porque concorrerá para que todos melhor saibam defender a saúde, trabalhar mais eficientemente, viver melhor em seu próprio lar e na sociedade em geral" (PAIVA 2015, p. 207).

Ao lançá-la, em janeiro de 1947, o Ministro da Educação explicava que muitos de nossos problemas sociais deviam ser sanados "pela recuperação da grande massa da população brasileira ainda desprovida de instrução" para que fosse possível organizar a vida do país em bases democráticas (PAIVA, 2015, p. 209). 
As ações nacionais que daí se desdobraram foram produto do contexto no qual o Brasil se encontrava, em que as condições internas, favorecidas pelo fim do Estado Novo, recolocavam o país no caminho da redemocratização. Pode-se acrescentar ainda, a ampliação do contingente de eleitores, já que a lei em vigor excluía os analfabetos do processo eleitoral.

Nesse período, muitas críticas foram feitas em relação a Campanha de Educação de Adultos, no que se referia a questões administrativas, financeiras, bem como a sua orientação política, pois conforme afirma Paiva:

Seu fundamento político, ligado a ampliação das bases eleitorais, se acompanhava
das ideias de "integração" como justificação social e de "incremento" da
produção" como justificação econômica. Era preciso impedir a desintegração
social, lutar pela paz social e promover a utilização ótima das energias populares
através da recuperação da população analfabeta que ficaria a margem do processo
de desenvolvimento do país (PAIVA, 2015, p. 207).

Assim, a ideia de integração descrita acima, trata-se de concretizar a ordem social vigente, ampliando a participação da população dentro do sistema estabelecido.

No que se refere ao plano político da Campanha, Paiva (2015), destaca que havia a preocupação no que se refere ao combate às ideias anarquistas e socialistas, pois "as grandes massas, relegadas a um plano secundário de ignorância e estacionamento, eram presas fáceis de ideologias nocivas nas mãos dos demagogos anarquistas".

Vemos, portanto, que toda a Campanha se orientava a partir das ideias de funcionamento da democracia liberal, e algumas vezes de combate a ideologias contrárias e de ampliação das bases eleitorais do país. Ela seria o instrumento para que a população, através do voto, participasse da vida política do país dentro dos princípios da democracia liberal (PAIVA, 2015, p. 210).

Porém, a Campanha parece ter contribuído para o enfraquecimento de algumas oligarquias tradicionais na medida em que muitos novos eleitores escaparam ao controle dos "currais eleitorais" dominantes, fortalecendo as dissidências oligárquicas - em geral mais abertas, pelo seu próprio caráter de oposição - e possibilitando a desobediência eleitoral aos líderes tradicionais (PAIVA 2015, p. 210).

Paiva (2015) traz como exemplo as eleições para a Presidência da República no ano de 1950 e 1960, quando é possível observar que muitas pessoas não obedeceram às lideranças políticas tradicionais. Segundo a autora há a suposição que a Campanha tenha colaborado para isso.

Em se tratando de índices, no que se refere à taxa de analfabetismo, Paiva (2015) afirma que na época a Campanha contribuiu para a queda das taxas de analfabetismo "(em 5,53 entre 1940/50; em 11,21 entre 1950/60) ela possibilitou um aumento significativo do número de eleitores no período". 
Tal acontecimento deu origem às sucessivas acusações de que o programa havia se transformado numa "fábrica de eleitores", e na medida em que seu aspecto de seriedade técnica ia se enfraquecendo, tornava-se mais claro o seu papel político, concorrendo para o crescimento das bases de representação política do país (PAIVA, 2015).

Para compreendermos a situação, retomamos a ideia de que os organizadores da Campanha consideravam o analfabeto como marginal e incapaz, porém o preconceito não resistiu à própria prática educativa da Campanha que:

[...] obrigando os técnicos ao contato com os analfabetos, proporcionou ocasião para a reformulação das ideias relativas ao problema, abrindo caminho para as formulações do final da década de 50 que - baseadas na antropologia recolocarão o analfabeto em seu lugar como homem capaz, tal como era reconhecido antes de 1882 (PAIVA, 2015 p. 215).

No ano de 1947 também acontece o I Congresso Nacional de Educação de Adultos, sua realização se fez num clima de entusiasmo pela Campanha, todos ressaltavam a necessidade da educação dos adultos para que se pudesse fazer funcionar a democracia brasileira. Muitos apoiam a ideia do analfabeto como incapaz e defendem a alfabetização em nome do exercício da cidadania (PAIVA, 2015, p. 215).

Durante a realização do Congresso, as propostas responsabilizavam a falta de educação do povo por grande parte dos problemas nacionais. Por conseguinte, se reconhecia a necessidade de aumentar a oferta de educação à massa da população. De acordo com Paiva (1987, p. 187-182), ainda nesse congresso, permanecia a ideia do analfabeto como incapaz, baseada no slogan preconceituoso de Cândido Jucá Filho, professor catedrático do Colégio Pedro II, "Ser brasileiro é ser alfabetizado".

De certo modo, as conclusões do Congresso refletem a mobilização observada no campo da educação popular desde a reabertura política do final do Estado Novo. Entretanto, as experiências educativas comunicadas ao Congresso pelos grupos comprometidos com ideais socialistas e principais promotores da mobilização voltada para a criação de Universidades Populares, não chegaram sequer a ser transcritas, como as demais, nos Anais do Congresso (PAIVA, 2015, p. 216).

Dessa forma, torna-se aparente o descaso quanto às políticas educacionais de cunho socialistas, a autora ainda afirma o caráter precursor desse congresso para a preconceituosa Campanha. É importante ressaltar que a proposta de concepção desse congresso foi empreendimento dos delegados dos Estados e territórios, para debater problemas que implicavam na concretização da Campanha (PAIVA, 2015, p. 215).

Em 1949, aconteceu o Seminário Interamericano de Educação de Adultos, a organização do Seminário, foi motivada, segundo Paiva (2015, p. 222), pela apresentação da Campanha 
brasileira e seus primeiros resultados na III Conferência Geral da Unesco (Beirute, 1948). Tal apresentação provocou curiosidade, então para que a Campanha pudesse ser conhecida e discutida, foi programado um Seminário Interamericano, a ser realizado no Brasil sob patrocínio da Unesco e da Organização dos Estados Americanos.

A autora salienta que a presença de profissionais da educação de diversos países latinoamericanos, nos quais também se desenvolviam campanhas de educação de adultos, tinham por objetivo trocas de experiências, considerando que:

Através da análise das diversas experiências continentais, os participantes do Seminário pretendiam chegar à conclusões que permitissem assentar as bases para a adoção de um sistema de trabalho aplicável, com ligeiras variações, à realidade latino-americana em geral (PAIVA, 2015, p. 215).

Assim, a experiência da Campanha brasileira despertava entusiasmo, mas não era adotada como modelo, mas sim, como embasamento para estudos críticos em relação às experiências de outros países. Considerando que os participantes desse Seminário adotavam bases educacionais que se adaptassem à realidade de seus países, surgiu a elaboração de um Manual de Educação de Adultos atendendo aos anseios aludidos de um trabalho aplicável à realidade latino-americana, que poderia ser adaptado a cada país, mas que não inviabilizasse o combate ao analfabetismo.

O Manual assinalava para essa direção, ou seja, recusar a "ação extensiva” para abarcar uma "ação em profundidade". O método seria o da "ação comunitária", ou seja, de que os diferentes segmentos sociais praticassem interferências na educação de adultos de modo que fossem objetivadas experiências com base nos desenvolvimentos econômico, cultural e social, abrangendo o que a autora nomeia "ação de profundidade" (PAIVA, 2015).

Nesse período, duas outras Campanhas foram criadas, mas obtiveram poucos resultados efetivos, sendo a Campanha Nacional de Educação Rural em 1952 e a Campanha Nacional de Erradicação do Analfabetismo em 1958 (PAIVA, 2015).

A Campanha Nacional de Educação Rural realizada em 1952 surgiu inicialmente ligada a Campanha de Educação de Adolescentes e Adultos e caracterizou-se, no período de 1952 a 1956, como uma das instituições que promoviam o processo de desenvolvimento de comunidades no meio rural brasileiro. Nos primeiros anos, muitas esperanças se voltaram para a aplicação dos princípios combinados da "organização social de comunidade" com as influências recebidas das Missões Rurais mexicanas e das recomendações do Seminário Interamericano (PAIVA, 2015, p. 225).

Através da análise das diversas experiências continentais, os participantes do Seminário pretendiam chegar à conclusões que permitissem assentar as bases 
para a adoção de um sistema de trabalho aplicável, com ligeiras variações, à realidade latino-americana em geral (PAIVA, 2015, p. 215).

Sob essa perspectiva a autora acrescenta que a Campanha pretendia contribuir para acelerar o processo evolutivo do homem rural, despertando-lhe o espírito comunitário, a ideia de valor humano e o sentido de suficiência e responsabilidade para que não se acentuassem as diferenças entre a cidade e o campo em detrimento do meio rural onde tenderiam a enraizar-se a estagnação das técnicas de trabalho, a disseminação de endemias, a consolidação do analfabetismo, a subalimentação e o incentivo às superstições e crendices.

Porém, as ações eram desvinculadas da reflexão sobre os métodos educativos a serem empregados na comunidade e sociedade como um todo e até mesmo sobre o modo de produção, sua formação social e consequências.

De acordo com Paiva (1987, p. 197) a criação da Campanha Nacional de Educação Rural, que inicialmente atuou ligada à Campanha de Educação de Adultos e Adolescentes e que vigorou até 1963, pode ser analisada como um dos pontos altos do movimento em favor do ensino rural.

A Campanha Nacional de Erradicação do Analfabetismo foi realizada em 1958 e tinha como característica uma nova etapa nas discussões que envolviam o tema da educação de adultos. Paiva (1987, p. 213) observa que a Campanha surgiu precisamente quando se iniciava, no país, uma nova fase na educação de adultos: perante o reconhecimento da ineficácia das campanhas anteriores, os educadores mobilizaram-se em busca de novos recursos para o problema do analfabetismo. Segundo seus organizadores, necessário era rever a simples ação alfabetizadora, pois os mesmos a avaliavam como insuficiente.

No entanto, salientavam uma área a que se devia dar prioridade, ou seja, a educação de crianças e jovens, pois segundo suas considerações, a educação ainda poderia significar alteração em suas condições de vida. Essa Campanha sofreu as dificuldades enfrentadas por todas as campanhas do MEC, até sua extinção, em 1963. De acordo com Paiva (2015), essa Campanha apresentava ações dispersas e desarticuladas, realidades presentes em campanhas anteriores e que os projetos que nela foram propostos eram mais uma forma de superação de críticas, subsídios que somados determinaram sua extinção.

Segundo Paiva (2015) o declínio das Campanhas chega ao auge em 1958 quando é convocado o II Congresso Nacional de Educação de Adultos, onde se reconhece de público o fracasso do programa do ponto de vista propriamente educativo. Os Anais do Congresso de 1958 são efetivamente, o único documento que nos permite observar amplamente até onde havia chegado o desgaste das Campanhas. Através dele observamos que o problema de pagamento aos 
professores era um dos mais sérios enfrentados pelas Campanhas e grandemente responsáveis pelo fracasso das suas atividades. A autora destaca que:

Representantes de vários Estados chamaram a atenção para a irrisória gratificação oferecida aos professores, com a qual só era possível aliciar um corpo docente despreparado e incompetente [...] outras críticas se faziam também no que concerne às condições de funcionamentos das classes, por falta de verba para resolver problemas de iluminação no interior ou para a aquisição de material escolar (PAIVA, 2015, p. 221).

Tais críticas conduziram a uma nova visão sobre o problema do analfabetismo e a consolidação de um novo paradigma pedagógico, tendo como referência o pensamento de Paulo Freire, que inspirou os principais programas de alfabetização e educação popular realizados no país no início dos anos de 1960 (SOARES, 2001).

Diante desses aspectos, o Congresso Nacional de Educação de Adultos, realizado em 1958, teve a finalidade de avaliar as ações realizadas na área e, visando propor soluções apropriadas para as questões apresentadas, como por exemplo, a inadequação do material didático e a qualificação do professor, bem como o estado precário dos prédios escolares. Paiva (2015) afirma que [...] a resposta às solicitações do Congresso de 1958 que concluíra pela inadequação dos programas existentes e pela necessidade da busca de novas diretrizes, em face das novas condições da vida política, social e econômica do país.

Finalmente, com os movimentos voltados para a promoção da cultura popular, valorizando as expressões artísticas e culturais do povo, o combate ao preconceito torna-se mais compacto e o sistema Paulo Freire - desenvolvido a partir do conceito antropológico de cultura - e sua difusão serão de fundamental importância para formar uma nova imagem do analfabeto, como homem capaz e produtivo, responsável por grande parcela da riqueza da Nação (PAIVA, 2015, p. 233).

Nesse sentido, como aponta Romanelli (2005, p. 71), diante de um discurso que situava a educação como caminho para restauração social, que se tratava da delegação da qual Paulo Freire fazia parte, que propôs uma educação baseada no diálogo. A proposta envolvia uma educação capaz de atender as características socioculturais das camadas populares e ao mesmo tempo estimular sua participação na realidade social. Outra questão relevante consiste em registrar que nesse congresso se discutiu, também, a Lei de Diretrizes e Bases da Educação Nacional - LDB e, por conseguinte, foi elaborada em 1962 o Plano Nacional de Educação - PNE sendo extintas as campanhas nacionais de educação de adultos em 1963. 


\section{CONTRIBUIÇÕES DE PAULO FREIRE NA EDUCAÇÃO DE JOVENS E ADULTOS}

Na década de 1960 o pensamento de Paulo Freire destaca-se juntamente com a sua proposta para a alfabetização de adultos inspirando os mais notáveis programas de alfabetização do Brasil. Em 1963, Freire é encarregado de organizar e desenvolver um Programa Nacional de Alfabetização de Adultos - PNAA. O convite foi feito pelo Presidente João Goulart e pelo Ministro da Educação Paulo de Tarso Santos. Em relação ao PNAA, Eugênio (2004) diz: "aprovado pelo Decreto 53.465, de 21 de janeiro de 1964, o Plano Nacional de Alfabetização de Adultos orientados pela proposta de Paulo Freire previa a instalação de 20 mil círculos de cultura, que alfabetizaria dois milhões de pessoas" (EUGÊNIO, 2004, p. 42-43).

Segundo Paiva (1973) o Método sistematizado por Paulo Freire, em 1962, preconizava que a educação haveria de ser corajosa, propondo ao povo a reflexão sobre si mesmo, sobre seu tempo e suas responsabilidades. Esta educação exigiria um método que permitisse ao educador ajudar o homem a ajudar-se, a fazer-se agente de sua própria recuperação através de uma postura conscientemente crítica diante de seus problemas. Ela deveria partir de situações concretas e se realizar através do diálogo, partindo da utilização de palavras geradoras nesse processo de alfabetização pela conscientização.

De acordo com o método Paulo Freire, o processo de ensino deveria possuir significado para quem aprendia, para tanto, as palavras geradoras deveriam ser carregadas sentido. A perspectiva de ensino e aprendizagem proposta por Paulo Freire considerava ser importante todos os saberes adquiridos pelos alunos adultos ao longo da vida, e estes saberes deveriam ser levados para as salas de aula, agregando esses saberes aos conteúdos propostos durante o processo de alfabetização, permitindo que o processo de ensino e aprendizagem pudesse ser transformado em educação politizada.

Paulo Freire (1990) condenava a utilização de cartilhas para alfabetizar adultos, instrumento pedagógico que em anos anteriores foram produzidos em larga escala, por ser demasiadamente limitadas e domesticadoras, esvaziadas de sentido para o aluno adulto, distinguindo aquele que ensina, daquele que aprende, pois, para Paulo Freire o professor que ensina também aprende, tanto quanto o aluno que aprende e ensina com sua vivência de mundo.

Para tanto, Paulo Freire propôs em seu método utilizar a cultura popular que se encontrava no meio social do aluno, sendo necessário portanto, organizar o pensamento do homem analfabeto, transformar seus pensamentos e visão sobre o universo em que ele se encontrava. Somente através do diálogo instigador existente entre professor e aluno isso poderia acontecer:

Paiva (1987) descreve criticamente esse momento histórico e educacional da época, que mudou a visão de educação voltada para grande parcela da população brasileira, que passa a 
escrever sua história como alunos, especialmente quando Paulo Freire implantou seu método de educação:

O método Paulo Freire para a educação de adultos, sistematizado em 1962, representa tecnicamente uma combinação original das conquistas da teoria da comunicação, da didática contemporânea e da psicologia moderna. Entretanto, o método derivava de ideias pedagógicas e filosóficas mais amplas: não era uma simples técnica neutra, mas todo um sistema coerente no qual a teoria informava a prática pedagógica e seus meios (PAIVA, 1987, p. 251).

Paulo Freire preconizava a transformação da sociedade através do diálogo pedagógico. Paiva (1980) afirma que o diálogo empregado na forma de ensinar, conforme defendia Paulo Freire, era realmente tornar o homem servil e medroso, num homem capaz de intervir e participar usando para isso, a razão e a crítica.

Para Paulo Freire, o diálogo era um instrumento de combate da dominação e da massificação, sendo o caminho para as questões que envolvessem o ordenamento político da sociedade e em todos os sentidos de desenvolvimento humano, propiciando a transformação interior dos indivíduos para que esses se tornassem sujeitos de sua própria alfabetização e não objetos.

Porém, conforme destaca Paiva (1987), o governo brasileiro no período entre os meses finais de 1963 e primeiros meses de 1964, sentiu-se amedrontado com o poder que a alfabetização realizada nos primeiros anos da década de 1960 por Paulo Freire, pudesse se tornar um processo político incontrolável a favor do povo, efeitos esses que seriam perigosos para a estabilidade do regime que estava prestes a se instalar no País.

\section{IMPLANTAÇÃO DO MOVIMENTO BRASILEIRO DE ALFABETIZAÇÃO E OUTROS PROGRAMAS DE ALFABETIZAÇÃO}

Com a tomada do poder pelos militares, o chamado Golpe Militar, esse trabalho de alfabetização experimentou uma ruptura, porque o pensamento freiriano era encarado como uma ameaça à ordem instalada. Seguido pela extinção do Programa via Portaria 237 de 14 de abril de 1964, deu-se o exílio de Paulo Freire e a instauração de programas assistencialistas e conservadores para alfabetização de adultos (PAIVA, 2015). A proposta pedagógica dominante naquele momento desconsiderava a migração rural-urbana, intensa naquele período, e dava primazia a um modelo industrial-urbano com padrões capitalistas de produção e consumo.

Os anos de 1961 a 1963 foram marcados pelo período de efervescência política e cultural e por um ambiente de reformas de base preconizadas pelo governo e pela organização e mobilização popular na vida política nacional. Em 1962, surge o primeiro Plano Nacional de 
Educação, organizado quando já estava vigente a primeira Lei de Diretrizes e Bases da Educação Nacional, no 4.024, de 1961. Em 1966, foi feita uma nova revisão do Plano Nacional de Educação (PNE) "que se chamou Plano Complementar de Educação, que introduziu importantes alterações na distribuição dos recursos federais" (PNE, 2000, p. 6). Esses aportes financeiros canalizados para a Educação de Jovens e Adultos tinham como objetivo o controle ideológico (PAIVA, 1987).

Em resposta à necessidade de redução do analfabetismo, foi criado, em 1967, pela Lei 5.379, de 15 de dezembro, o Movimento Brasileiro de Alfabetização (MOBRAL). Para Paiva (1987), a implantação desse novo modelo de organização do ensino no Brasil, nos anos que se sucederam ao regime militar, ocorreu através das ações desenvolvidas pelo MOBRAL, com a incumbência de promover a educação dos adultos analfabetos e cooperar com movimentos isolados de iniciativa privada.

O referido Movimento pauta-se no assistencialismo e conservadorismo. Com o MOBRAL, o governo assume o controle da alfabetização de adultos, atendendo um público entre 15 a 30 anos, é oferecida uma alfabetização funcional, apropriação de técnicas básicas de leitura, escrita e cálculo. Esse Movimento não demonstrava nenhuma preocupação com a formação integral do homem. O MOBRAL assume a educação como investimento, qualificação de mão-de-obra para o desenvolvimento econômico. A realidade existencial não é questionada.

Em 1969, diante das pressões do governo militar, o MOBRAL afastou-se da proposta inicial, apresentando-se como um programa que contava com recursos significativos, mantendo rígido controle sobre a orientação, supervisão pedagógica e produção de materiais didáticos, assegurando, assim, os interesses políticos dos governos militares. Elementos como crítica e problematização, na educação de jovens e adultos propostos por Paulo Freire, perderam o seu lugar. As metodologias e o material didático esvaziaram-se quanto àqueles elementos.

Durante a década de 70, o movimento expandiu-se por todo o país, derivando o Programa de Educação Integrada (PEI), o qual era uma síntese do curso primário e possibilitava a continuidade de estudos. Neste mesmo período, foi implantado um projeto de educação via rádio, denominado Projeto Minerva. Todas as emissoras de rádio do país foram obrigadas a transmitir em determinado horário a programação educativa. Tal experiência teve como elementos negativos a oscilação de matrículas e as evasões durante o curso (CASCAVEL, 2008).

Reiterando a organização do MOBRAL nesse período, Beisiegel (1997) afirma que a partir de 1970, o MOBRAL atuou através do Programa de Alfabetização e do Programa de Educação Integrada, sendo este uma versão compactada das quatro séries do antigo ensino primário. Depois passou a atuar também mediante convênios celebrados com as Comissões Municipais e Secretarias de Educação e com outras entidades públicas e privadas. 
Com a Lei de Diretrizes e Base da Educação (LDB) 5.692/71, que implantou o Ensino Supletivo, a educação de adultos recebe, pela primeira vez, a atenção governamental como uma tarefa contínua do sistema de ensino. O Artigo 24, alínea a diz: "suprir a escolarização regular para os adolescentes e adultos que não tenham seguido ou concluído na idade própria”.

Assim, pode-se dizer que no contexto educacional, a legislação que, pela primeira vez, faz referência à EJA foi a LDB para o ensino de $1^{\circ}$ e $2^{\circ}$ graus no $5692 / 71$ e o Parecer 699/72, do Conselho Nacional de Educação, conforme segue:

A Lei de Diretrizes e Bases da Educação Nacional (LDB) 5.692/71, ao estabelecer as diretrizes e bases do ensino de $1^{\circ}$ e $2^{\circ}$ graus, não incluiu no Sistema de Ensino aqueles que não estudaram em idade considerada apropriada (dos 7 aos 14 anos). Criou, no entanto, um sistema de atendimento paralelo ao sistema de Ensino Regular. O Ensino Supletivo, nesse período, configurou-se em um subsistema do Ensino Regular e abrangia o processo de alfabetização, a aprendizagem, a qualificação, algumas disciplinas e também a atualização. Os cursos podiam ser a distância (correio), com a certificação via exames, realizados em estabelecimentos oficiais ou não, sob a responsabilidade dos Conselhos Estaduais de Educação. O Parecer 699/72 do Conselho Nacional de Educação, elaborado por Valnir Chagas, regulamentava o então ensino supletivo e lhe atribuía quatro funções: suplência, substituição compensatória do ensino regular via cursos ou exames, suprimento, complementação do inacabado por meio de aperfeiçoamento e atualização; aprendizagem e qualificação, que só teriam certificados de conclusão nas etapas de $5^{\mathrm{a}}$ a $8^{\mathrm{a}}$ séries ou $2^{\circ}$ grau quando incluíssem disciplinas, áreas de estudo e atividades que os tornassem equivalentes ao ensino regular (BRASIL, 2000).

Compreende-se, portanto, que esta modalidade de ensino foi regulamentada tendo as seguintes funções básicas: a suplência, o suprimento, a aprendizagem e a qualificação, mediante a oferta de cursos e exames supletivos (SOARES, 2001, p. 206).

Por um lado, esta organização pode ser vista como uma possibilidade de concluir antecipadamente os estudos para aqueles em que as condições de vida e de inserção no mercado de trabalho atuam como impedimento ou como dificuldade para frequentar o Ensino Regular, ainda que noturno. Por outro lado, abre a possibilidade para o abandono da escola, para que, no momento em que completar 15 anos, o adolescente possa obter certificado de conclusão do Ensino Fundamental, e aos 18 possa prestar exames para conclusão do Ensino Médio (SAVIANI, 1997, p. 214).

É importante ressaltar, que a organização curricular e a matriz do ensino supletivo seguiam a proposta curricular do ensino regular, porém de forma compactada, não denotando especificidade à população jovem e adulta no processo de escolarização. O ensino supletivo foi apresentado, em princípio, como uma modalidade temporária, de suplência, para os que precisavam 
comprovar escolaridade no trabalho e para os analfabetos. Porém, tornou-se uma forma de ensino permanente, de oferta necessária, considerando a crescente demanda (PARANÁ, 2006, p. 19).

De acordo com Macedo (2006), na década de 1980, com a abertura política e a redemocratização do país, os movimentos sociais foram impulsionados a prosseguir e a ampliar seus projetos de atendimento à demanda de EJA, porém, com a desvinculação de alguns municípios do MOBRAL, este movimento foi perdendo forças, e no ano de 1985, foi extinto definitivamente. Constata-se poucos avanços durante o período de vigência do MOBRAL, sendo que, das quarenta milhões de pessoas que durante 15 anos frequentaram este movimento, apenas $10 \%$ foram alfabetizadas (PARANÁ, 2005, p. 13).

Com a extinção do MOBRAL, foi criada a Fundação Nacional para Educação de Jovens e Adultos - Fundação Educar, a qual passa a dar sustentação técnica e financeira às prefeituras municipais e instituições da sociedade civil que ofertavam educação básica para jovens e adultos. Seu período de vigência foi assinalado por um esgotamento das políticas públicas para jovens e adultos no âmbito do governo federal.

Macedo (2006) explica que a Fundação Educar, em vez de instituição de ação direta, atuou como órgão de fomento e de apoio técnico, representando, em muitos aspectos, a continuidade do MOBRAL e, em 1990 foi extinta. Para a escolarização básica de Jovens e Adultos, essa medida representou um marco no processo de descentralização, e novas propostas surgiram no cenário nacional. Observa-se, nesse contexto, uma diversidade de programas e de projetos com diferentes objetivos e concepções.

Na década de 90, o Brasil passou por um período de reformas educacionais, as quais tiveram seu início firmado na Conferência Mundial de Educação para Todos, realizada em Jontiem, na Tailândia, em março de 1990.

\section{A EDUCAÇÃO DE JOVENS E ADULTOS APÓS CONSTITUIÇÃO FEDERAL DE 1988 E APROVAÇÃO DA LDB Nº 9.394/96}

As políticas educacionais mais expressivas relacionadas à EJA têm seu início com a Constituição Federal de 1988, pois é ela que garante, no Título dos Direitos Individuais e Coletivos, o direito à Educação a todos os cidadãos brasileiros, visto que o artigo 208 diz que:

Art. 208. O dever do Estado com a educação será efetivado mediante a garantia de:

I - Ensino fundamental, obrigatório e gratuito, assegurada, inclusive, sua oferta gratuita para todos os que a ele não tiveram acesso na idade própria (BRASIL,1988). 
Observa-se, por meio deste texto a preocupação com aqueles que não tiveram condições de escolarização em idade própria. Para tanto, em cumprimento à Constituição Federal de 1988 a

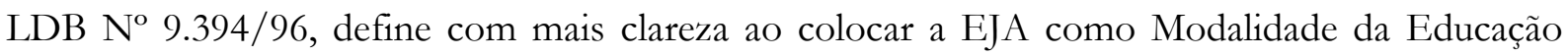
Básica: “a Educação de Jovens e Adultos será destinada àqueles que não tiveram acesso ou continuidade de estudos no Ensino Fundamental e Médio, na idade própria” (BRASIL, 1996).

Dessa forma, a aprovação da Lei 9.394/96 representou um avanço significativo em termos de democratização do ensino, priorizando várias possibilidades educativas no processo de escolarização que se ampliaram, e tomaram forma educativa para compensar o tempo perdido por muitas pessoas que não frequentaram a escola em idade série compatíveis.

Porém, ao estabelecer o padrão de distribuição dos recursos públicos estaduais e municipais em favor do ensino fundamental de crianças e adolescentes, o Fundo de Manutenção e Desenvolvimento do Ensino Fundamental e de Valorização do Magistério - FUNDEF deixou parcialmente descoberto o financiamento de três segmentos da educação básica - a educação infantil, o ensino médio e a educação básica de jovens e adultos, o que restringiu as fontes de financiamento e desestimulou os gestores a ampliarem as matrículas nessa modalidade de ensino.

A EJA foi contemplada somente com a aprovação do Fundo Nacional de Desenvolvimento da Educação Básica e de Valorização do Magistério - FUNDEB, que está em vigor desde janeiro de 2007, devendo perdurar até 2020. Ele foi regulamentado pela seguinte legislação: Medida Provisória no 339, de 29 de dezembro de 2006; Lei no 11.494, de 20 de junho de 2007; Decreto ${ }^{\circ}$ 6.253, de 13 de novembro de 2007 e Decreto no 6.278, de 29 de novembro de 2007. Em linhas gerais, podemos afirmar que o FUNDEB vem seguindo em linhas básicas o FUNDEF, mas corresponde a um importante avanço, caracterizado pela ampliação da abrangência do fundo, pois:

[...] além do ensino fundamental de 9 anos, são beneficiários dos recursos do fundo a educação infantil (creches e pré-escolas), o ensino médio, a educação de jovens e adultos (EJA), nos meios tanto urbanos quanto rurais, a educação especial, a educação indígena e quilombola e também a educação profissional integrada ao ensino médio (Lei 11. 494/2007, Art. 10).

São destinatários dos recursos do FUNDEB, os Estados, Distrito Federal e Municípios que oferecem atendimento na Educação Básica. Embora reconheçamos esses avanços, Carvalho (2012) aponta que diversos autores acreditam que o FUNDEB ainda não resolve o problema do financiamento da educação. Para Saviani (2008b), por exemplo, seria necessário praticamente duplicar o valor destinado à educação (CARVALHO, 2012, p. 277).

\section{CONCLUSÃO}


Desse breve resgate da trajetória histórica da educação de jovens e adultos no Brasil, é possível notar a predominância de campanhas e movimentos desenvolvidos, em geral, a partir da administração federal, com o envolvimento de organizações da sociedade civil com vistas à efetivação de propostas ambiciosas de eliminação do analfabetismo e formação de mão-de-obra em curtos espaços de tempo.

Verificamos, ao longo dos anos, que foram tímidos os avanços significativos, legais ou pedagógicos na educação de jovens e adultos. Houve ausência de políticas para ampliar a oferta, falta ou inadequação de materiais didáticos de apoio referentes a essa modalidade de ensino, e escasso empenho na formação inicial e continuada de professores para atuar nessa modalidade. No entanto, alguns municípios e estados têm assumido a responsabilidade pela Educação de Jovens e Adultos, reafirmando seu compromisso com essa parcela da população.

É válido destacar que apesar de conquistas relacionadas ao aumento do atendimento aos jovens e adultos, a elaboração da Proposta Pedagógica das Escolas que ofertam esta modalidade de ensino, a elaboração da DCEs, as quais abordam sobre a organização da oferta de forma geral, como, processo ensino/aprendizagem, concepção de avaliação, entre outros aspectos, observa-se que ainda há dificuldades enfrentadas no interior das escolas, desde problemas de aprendizagem, evasão escolar, financeiro e até questões relacionadas à ordem administrativas.

Importa neste momento de finalização, pontuar que sim, esta modalidade de educação teve muitos avanços juntamente com as transformações políticas, econômicas, sociais e culturais da sociedade brasileira nos últimos anos. Porém é necessária uma análise mais aprofundada para que as políticas educacionais da (EJA) sejam aperfeiçoadas, evitando, sobretudo, a evasão escolar que, por consequência, pode contribuir para a diminuição do analfabetismo.

Além do mais durante esta trajetória de estudo reforcei ainda mais alguns conceitos existenciais e profissionais, entre os quais a crença de que para trabalhar com a EJA, além de uma base teórico-metodológica, há de se entender de gente e suas aprendizagens. Entender como o adulto aprende e como se envolve com a aprendizagem. Entender, especificamente como aprende $\mathrm{o}$ adulto humilde, do interior, de zonas periféricas e pertencentes às minorias, porque, infelizmente é nestes estratos sociais que se concentram a maioria dos educandos desta modalidade. Isso é essencial. Não porque haja diferenças estruturais, antagônicas ou de cunho intelectivo entre pobres e ricos, moradores do interior e da cidade, da periferia e do centro. Mas há diferenças culturais e diferenças de propósito, além de distintas maneiras de olhar mundo. O entendimento desta perspectiva, destes olhares, permite que possamos contribuir para ter uma educação de qualidade. 


\section{REFERÊNCIAS}

BEISIEGEL, C. de R. Participação Popular na melhoria do ensino público. Revista Brasileira de Educação. Rio de Janeiro: n. 1, p. 93-99, jan/abr., 1997.

BRASIL. Constituição Federal do Brasil. Brasília: Senado Federal, 1988.

BRASIL. Lei de Diretrizes e Bases da Educação Nacional: Lei n. 9.394/96. Brasília, 1996.

CARValHO, Elma Júlia Gonçalves de. Políticas Públicas e Gestão da Educação no Brasil. Maringá: Eduem, 2012.

CUNHA, L.A; GOÉ, M. de. O golpe na educação. Rio de Janeiro, Jorge Zahar Ed., 1999.

EUGÊNIO, Benedito Gonçalves. O Currículo na Educação de Jovens e Adultos: entre o formal e o cotidiano numa escola municipal em Belo Horizonte. Belo Horizonte: PUC/MG, 2004 (Dissertação de Mestrado em Educação)

FALEIROS, Vicente de Paula. As funções da política social no capitalismo. In: A política social do estado capitalista: as funções da previdência e assistência sociais. 12. Ed. São Paulo: Cortez, 2009, p. 46-84.

FREIRE, Paulo. Alfabetização: leitura da palavra leitura do mundo / Paulo Freire, Donaldo Macedo: tradução Lólio Lourenço de Oliveira. - Rio de Janeiro: Paz e Terra, 1990. $2^{a}$ Reimpressão $-1994$.

HADDAD, Sérgio. A educação continuada e as políticas públicas no Brasil. RIBEIRO, V. M. (Org.). In: Educação de Jovens e Adultos: novos leitores, novas leituras. Campinas: Mercado das Letras, Ação Educativa, 2001.

HADDAD, Sérgio; DI PIERRO, Maria Clara. Satisfação das necessidades básicas de aprendizagem de jovens e adultos no Brasil: contribuições para uma avaliação da educação para todos. São Paulo: Ação Educativa; São Paulo em Perspectiva, vol.14, n.1, p.29-40, mar. 2000. Disponível em:<http://www.scielo.br>. Acesso em: 19 de fevereiro 2019.

MACEDO, P. F. Um olhar sobre a EJA. Revista Eletrônica, 2006.

ORGANIZAÇÃO DAS NAÇÕES UNIDAS PARA EDUCAÇÃO, CIÊNCIA E CULTURA. Educação Para Todos: Atingindo nossos Compromissos Coletivos. Dakar: Cúpula Mundial de Educação, 2000. Disponível em:<http://www.unesco.cl/biblioteca/documentos/ept $>$. Acesso em: 19 de fevereiro 2019.

PAIVA, Vanilda Pereira. História da Educação Popular no Brasil: educação popular e educação de adultos. São Paulo: LOYOLA, 2015.

PAIVA, Vanilda Pereira. Educação Popular e Educação de Adultos: contribuição à história da educação brasileira. São Paulo: LOYOLA, 1973.

PAIVA, Vanilda Pereira. Educação Popular e Educação de Adultos/ Vanilda Pereira Paiva. Temas Brasileiros - II. Instituto Brasileiro de Desenvolvimento (IBRADES), São Paulo: Edições Loyola: 1987. 
PAIVA, Vanilda Pereira. Paulo Freire e o Nacionalismo-Desenvolvimentista / Vanilda Pereira Paiva. Coleção Educação e Transformação. Volume 3. - Editora Civilização Brasileira S.A. Edições UFC. Rio de Janeiro, 1980.

PARANÁ. Secretaria de Estado da Educação - SEED. Diretrizes Curriculares da Educação de Jovens e Adultos. - Curitiba. SEED, 2006.

PNE em movimento: Caderno de Orientações para o Monitoramento e Avaliação dos Planos $\begin{array}{llll}\text { Municipais de } \quad \text { Educação } & \text { (BRASIL, Disponível }\end{array}$ em: $<$ https: / cascavel.atende.net/?pg=subportal\&chave $=26 \# ! /$ tipo/pagina $/$ valor $/ 651>$ Acesso em: 19 de fevereiro 2019.

ROMANELLI, Otaiza de Oliveira. História da educação no Brasil (1930-1973). 29.ed. Petrópolis: Vozes, 2005.

SALES, Sheila Cristina Furtado. Educação de Jovens e Adultos no Interior da Bahia. São Carlos: UFSCar/SP, 2008. (Tese de Doutorado em Educação)

SAVIANI, D. A nova lei da educação: trajetória e perspectivas. $7^{\mathrm{a}}$ ed. Campinas: SP: Autores Associados, 2001.

Secretaria Municipal de Educação. Proposta Pedagógica da Educação de Jovens e Adultos. Vitória da Conquista. SMED, 2007.

SEVERINO, Antonio Joaquim. Metodologia do trabalho científico. 23. ed. São Paulo: Cortez, 2007.

SOARES, Leôncio José Gomes. As políticas de EJA e as necessidades de aprendizagem dos jovens e adultos. RIBEIRO, V. M. (Org.). In: Educação de Jovens e Adultos: novos leitores, novas leituras. Campinas: Mercado das Letras, Ação Educativa, 2001. 